\title{
Context Learning and the Effect of Context on Memory Retrieval in Lymnaea
}

\author{
James Haney and Ken Lukowiak ${ }^{1}$ \\ Department of Physiology and Biophysics, University of Calgary, Calgary, Alberta T2N4N1, Canada
}

\begin{abstract}
Aerial respiratory behavior in Lymnaea was operantly conditioned so that the animals perform aerial respiration significantly less often. Using the standard training procedure (pond water made hypoxic by bubbling $\mathrm{N}_{2}$ through it) both food-deprived and fed animals learned and exhibited long-term memory (LTM). However, food-deprived animals exhibited neither learning nor memory when trained under a condition in which the hypoxic pond water also contained a food odorant (carrot, the food-odorant procedure). Fed animals, however, learned and exhibited LTM with the food-odorant procedure. Thus, the presence of the food odorant per se did not prevent learning or the establishment of LTM. Further experimentation, however, revealed that the ability of the snails to have recall (i.e., memory) for the learned behavior was dependent on the context in which memory was tested. That is, if animals were trained with the food-odorant procedure they could only exhibit recall if tested in the food-odorant context and vice versa with the standard training procedure. Thus, although fed animals could learn and show LTM with either training and testing procedure, LTM could only be seen when they were tested in the context in which they were trained.
\end{abstract}

Learning and memory are not a single process but are a constellation of distinct processes, each with its own rules (Milner et al. 1998). The acquisition of a skill constitutes learning, while the ability to retain that knowledge defines memory. Many different factors affect the ability to learn, to consolidate that learning into memory, and to allow the memory to be retrieved. Thus, for example, stress (de Quervain et al. 2000), inattention (Rees et al. 1999), and hunger (Murphy et al. 1998; Powell et al. 1998) may negatively affect our ability to learn, form the memory, and retrieve the memory. But how such factors do so at the neuronal level is not understood (Martin et al. 1997). A major contributing factor to this lack of understanding of how those factors and others affect learning and memory are the unavailability of suitable model systems in which direct examination of the neuronal mechanisms underlying learning and memory can be made.

We chose to study the neuronal mechanisms that underlie associative learning in the freshwater pond snail, Lymnaea stagnalis (for review, see Benjamin et al. 2000). An important homeostatic behavior of this organism, aerial respiration, can be operantly conditioned (Lukowiak et al. 1996). Operant conditioning is a form of associative learning produced by the presentation of a reinforcing stimulus to the subject after the occurrence of a particular behavior (Mackintosh 1974). The reinforcement can be positive, leading to an increase in the behavior, or negative, leading to a decrease in the specific behavior (i.e., aversive operant

${ }^{1}$ Corresponding author.

E-MAIL lukowiak@ucalgary.ca; FAX (403) 283-2700.

Article and publication are at www.learnmem.org/cgi/doi/ 10.1101/lm.34701. conditioning; Mackintosh 1974). The primary reason for choosing operant conditioning of aerial respiratory behavior is that it is mediated by a three-neuron central pattern generator (CPG; Syed et al. 1990). These neurons are both necessary and sufficient for aerial respiratory behavior (Syed et al. 1990). We have been able to show neural correlates of learning and its memory within the CPG circuit that mediates the behavior (Spencer et al. 1999).

Our previous work showed that the changes observed in aerial respiratory behavior following training are an example of associative learning (Lukowiak et al. 1996, 1998, 2000a). However, we have not previously examined the effect of stress, attention, or food availability on the ability of Lymnaea to learn, consolidate the memory, and retrieve the memory. We did this here by altering the context in which the snails were trained for associative learning and tested for memory retention. Context includes the concept of the surrounding conditions in which learning takes place and can include items such as food odorants. The notion of using different odors in various conditioning procedures is not new. For example, Sahley et al. (1990) used an odor as an adverse $\mathrm{CS}^{+}$and paired it with an attractive taste, while another odor $\left(\mathrm{CS}^{-}\right)$was explicitly unpaired with the attractive taste. This appetitive conditioning procedure dramatically increased the preference for the $\mathrm{CS}^{+}$odor but not for the $\mathrm{CS}^{-}$. Gerber and Menzel (2000) used different odors as signals of context and determined how context affected memory storage in bees. Thus, odor can be used as a signaling stimulus in different learning situations.

Context-specific learning and its memory have previously been shown in a number of different invertebrate model systems. For example, in Caenorhabditis elegans,

LEARNING \& MEMORY 8:35-43 @ 2001 by Cold Spring Harbor Laboratory Press ISSN1072-0502/01 \$5.00

$$
\begin{array}{lllllllllllllll}
L & E & A & R & N & I & N & G & \mathbf{Z} & M & E & M & O & R & Y \\
\text { www.learnmem.org } & & &
\end{array}
$$


Rankin (2000) showed in the course of training using a nonassociative procedure to produce habituation of an escape response that the animal makes use of contextual cues. Thus, the retention of habituation (i.e., memory) persisted significantly longer if the nematode was both trained and tested in the same chemosensory cue (i.e., context). Similarly, Hermitte et. al. (1999), using the crab Chasmagnathus, showed that altering the context affected negatively the ability of the crab to access a long-lasting, new protein-dependent memory. In Aplysia Colwill et al. (1988) showed a similar context-dependent form of memory of a tactile stimulus in their conditioning procedures.

Here we present data showing that a food odorant (the smell of carrot) can prevent learning and memory in fooddeprived Lymnaea. However, food-deprived snails can learn and do exhibit long-term memory (LTM) if trained and tested using the standard training procedure. The foododorant procedure does not per se prevent learning and memory, as non-food-deprived snails can learn and form LTM in the food-odorant context. However, snails trained with the food-odorant procedure behave as naive animals do when tested with the standard procedure (i.e., no LTM) and vice versa. Thus, context is important for memory retrieval. Developing procedures in Lymnaea that possibly mimic the effects of stress and inattention seen in humans may allow us to better understand how these factors interfere with learning and memory.

\section{RESULTS}

In these and all subsequent experiments reported here we operationally defined learning and memory. Learning was defined as the significant effect of repeated training on the number of attempted pneumostome openings (determined by an ANOVA, $P<0.05$ for each group of animals in a specific context, etc.). Thus, the number of attempted pneumostome openings in Session 3 had to be significantly less than the number of attempted openings in Session 1 (a post hoc Fisher's LSD protected t-test was used following the ANOVA analysis in all groups to determine if the values between sessions within each group were statistically significant, $P<0.05$ ). Memory was defined as there being no significant difference between the number of attempted pneumostome openings in the test session (Session 4) compared to the last training session (Session 3). In addition, the number of attempted openings in Session 4 had to be significantly different from the number of attempted openings in Session 1. If all the above criteria were met, we concluded that learning and memory were shown.

\section{Food Deprivation and Learning}

These initial experiments were performed to determine if learning and LTM could be shown in animals that were food deprived (i.e., without food for $5 \mathrm{~d}$ before testing). Fooddeprived Lymnaea $(n=24)$ were first trained and tested in the standard hypoxic procedure (i.e., without food odorant present; see Materials and Methods). In these animals, both learning and LTM were observed. That is, the number of attempted pneumostome openings significantly decreased over the three training sessions [ANOVA, $F(2,23)=3.2349$, $P=0.04]$. In addition, Session 1 was significantly different from Session 3 ( $P<0.05, n=24$; Fig. 1A). When tested 18 $\mathrm{h}$ later, these animals exhibited LTM. That is, the number of attempted pneumostome openings on Session 4 was not significantly different from Session 3 but was significantly different from Session $1(P<0.01)$.

A second group of food-deprived Lymnaea ( $n=24$; Fig. 1B) were trained and tested for LTM but this time with the food-odorant (the smell of carrot) hypoxic procedure. These animals neither learned nor exhibited LTM. That is, there was no significant effect of training on the number of attempted pneumostome openings [ANOVA, $F(2,23)=0.2612, P=0.7713]$. Thus, the number of attempted openings in Session 3 was not significantly different from Session 1 ( $P>0.05, n=24$; Fig. 2$)$. When LTM was tested $18 \mathrm{~h}$ later, the animals again did not show any significant decrease in the mean number of attempted pneu-

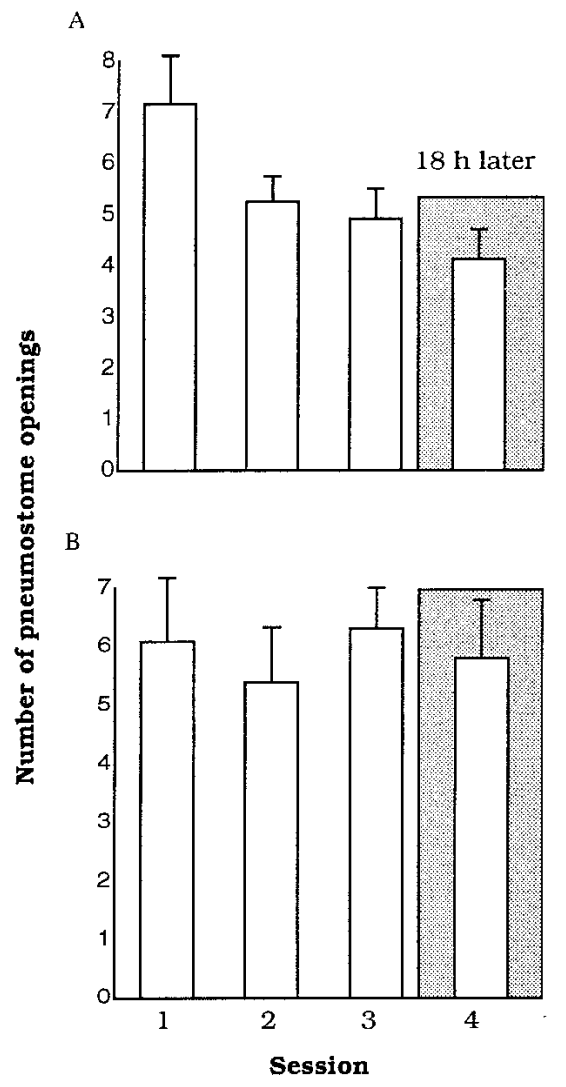

Figure 1 Different training procedures effect learning and memory in food-deprived snails. $(A)$ The use of the standard training procedure results in learning and memory. $(B)$ Learning and memory are not observed with the food-odorant procedure; $n=24$ in $A$ and $B$.

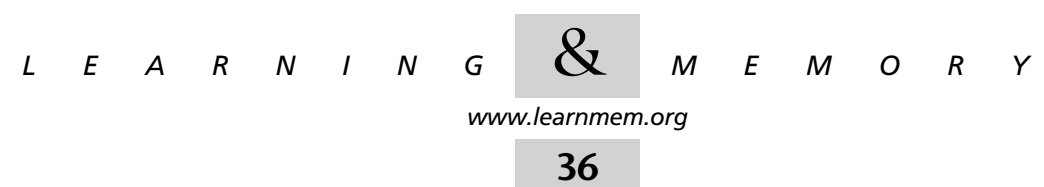




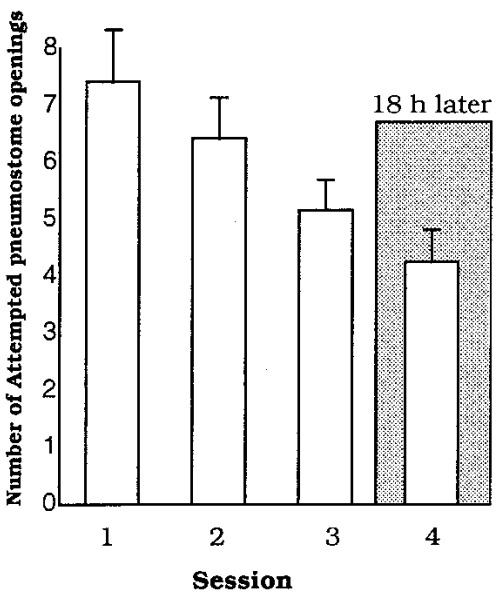

Figure 2 Learning and memory with the food-odorant procedure. Non-food-deprived animals ( $n=24$; fed lettuce) exhibit learning and have the abilities to form and retrieve memory when trained and tested with the food-odorant procedure.

mostome openings from that found in Session $1(P>0.05)$. Thus, food-deprived animals can learn and form LTM, but if a food odorant is present they neither learn nor remember. We conclude that the presence of the food odorant prevents associative learning and LTM when animals are fooddeprived.

Do the above data mean that snails cannot learn or remember when trained with the food-odorant procedure? We therefore sought to determine whether non fooddeprived animals could learn and show LTM when trained and tested with the food-odorant procedure.

Non-food-deprived Lymnaea (fed lettuce) were trained and tested with the food-odorant procedure. These animals showed both learning and LTM ( $n=27$; Fig. 2$)$. That is, there was a significant effect of training on the number of attempted pneumostome openings [ANOVA, $F(2,26)=3.3116, P<0.0453]$. The number of attempted pneumostome openings in Session 3 was significantly less than those in Session $1(P<0.05)$. Moreover, when these snails were tested $18 \mathrm{~h}$ later, the number of attempted openings was not significantly different from Session $3(P>0.05)$ but was significantly different from Session 1 (i.e., LTM was shown; $P<0.01)$. Therefore, the food-odorant procedure per se did not prevent learning or the establishment of LTM in Lymnaea.

\section{Memory Retrieval in a Different Context}

The following experiments were designed to ask the question: Would animals trained with the standard procedure that produces LTM be capable of memory retrieval when tested with the food-odorant procedure and vice versa?

Food-deprived Lymnaea were trained with the standard hypoxic procedure but were tested for memory with the food-odorant procedure. As expected, these animals ex- hibited learning [ANOVA, $F(2,26)=35.3741, P=0.0001$ ] Session 3 was significantly less than Session $1 \quad(P<0.01$, $n=27$; Fig. 3A). However, when tested for LTM some $18 \mathrm{~h}$ later with the food-odorant procedure, the number of attempted pneumostome openings was not significantly different than Session $1(P>0.05)$. Moreover, the number of attempted openings in Session 4 was significantly different from Session $3(P<0.01)$. These data are opposite to the results expected if the animals had both established LTM and could retrieve the stored memory. Thus, altering the context of the testing situation had a significant effect on whether the memory could be retrieved.

The data from the above experiment suggest that the context of the test situation is important for memory recall. However, it is possible that LTM was not exhibited because food-deprived snails were stressed or were made inattentive by the food odorant. To test this possibility we performed a similar experiment using non-food-deprived animals.

Non-food-deprived (fed lettuce) Lymnaea were trained

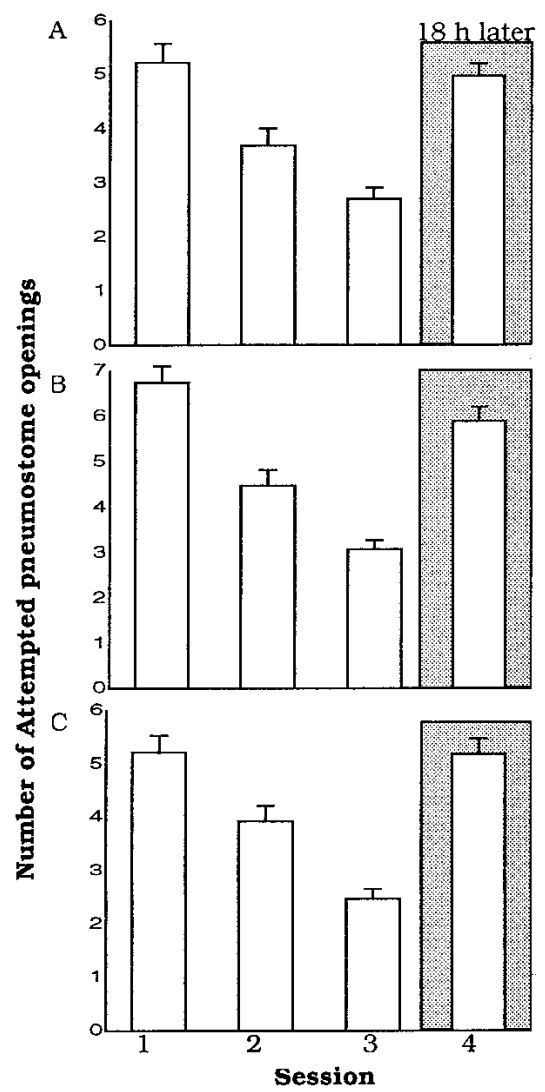

Figure 3 Learning but no recall of memory. (A) Food-deprived snails $(n=27)$ trained with the standard hypoxic procedure exhibited learning. However, when the context of the test session $(18 \mathrm{~h}$ later) was changed to the food-odorant procedure, the snails were unable to retrieve their stored memory. $(B)$ The same experiment with non-food-deprived snails $(n=27)$ trained with the standard procedure. (C) Non-food-deprived animals $(n=27)$ trained with the food odorant and tested with the standard procedure.

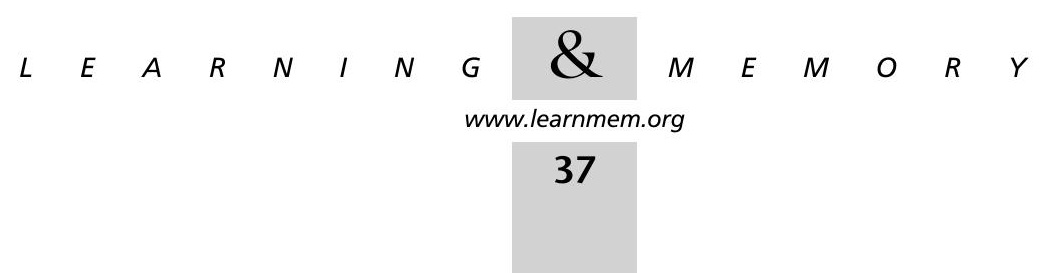


with the standard hypoxic procedure and then were tested for LTM with the food-odorant hypoxic procedure (Fig. 3B). As with the food-deprived animals (Fig. 3A), these animals exhibited learning but not LTM. That is, they showed learning $[$ ANOVA, $F(2,26)=41.9306, P<0.001)$. Session 3 was significantly different from Session $1(P<0.01, n=27$; Fig. $3 \mathrm{~B})$, but when tested for LTM with the food-odorant procedure, the animals behaved as if they had not been trained previously. Thus, the number of attempted pneumostome openings in Session 4 was not significantly different from Session 1 but were significantly different from Session 3 $(P>0.01)$.

Would the alteration of the testing context also affect memory recall when the training and test procedures were reversed? Non-food-deprived (fed lettuce) Lymnaea were trained with the food-odorant procedure but were tested with the standard hypoxic procedure. This experiment was the reverse of previous experiment (Fig. 3B) and gave a similar result. Learning was shown [ANOVA, $F(2,26)=34.2035, P<0.0001$; Session 3 was significantly different from Session 1 ( $P<0.01$; Fig. 3C] but LTM was not. That is, the number of attempted pneumostome openings in Session 4 was not significantly different from Session $1(P>0.05)$. Again, in the test session these animals behaved as naive animals would and showed no ability to retrieve the memory.

It could be argued that, because the animals had never experienced carrot smell in their life, this totally novel odorant completely blocked the snails' ability to retrieve their memory. We therefore repeated the above experiments but with the snails being fed carrot instead of lettuce for $5 \mathrm{~d}$ before any training or testing. These experiments were designed to uncover any interaction between the food source the animals had continual access to and their ability to learn and remember in different contexts. Lymnaea fed carrot rather than lettuce were trained with the food-odorant procedure (carrot) and tested for LTM in the food-odorant procedure (Fig. 4). As expected these animals exhibited learning [ANOVA, $F(2,25)=37.633, P<0.001$; Session 3 was significantly different from Session 1: $P<0.01, n=26$ ] and LTM Session 4 was not significantly different from Session 3 $(P>0.05)$ but was significantly different from Session 1 $(P<0.01)$. Thus, snails fed carrot could learn, form LTM, and retrieve memory when trained and tested with the food-odorant procedure.

The next series of experiments determined if animals fed carrot but trained with the standard hypoxic procedure would respond differently when LTM was tested with the food-odorant (carrot) procedure. Because these animals had continuous access to carrot before training ensued, when challenged in the LTM memory test with the carrot odorant, would they show LTM because carrot was no longer a novel odorant?

These animals learned [ANOVA, $F(2,25)=78.3424$,

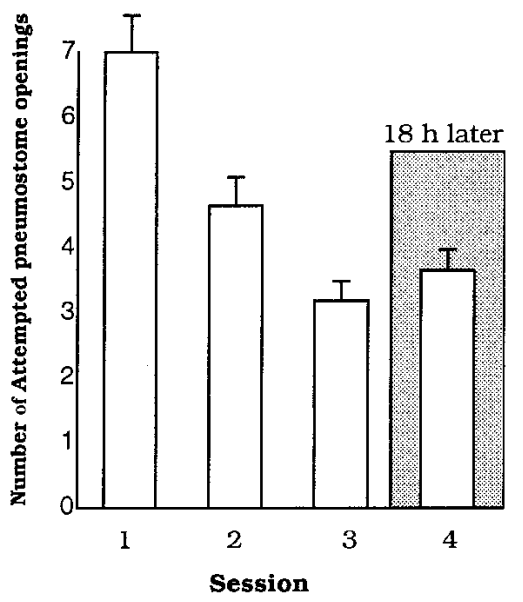

Figure 4 The food snails have access to does not affect learning or LTM. Snails $(n=27)$ were fed carrot rather than lettuce. When trained with the food-odorant procedure (carrot smell), they exhibited learning and long-term memory (LTM).

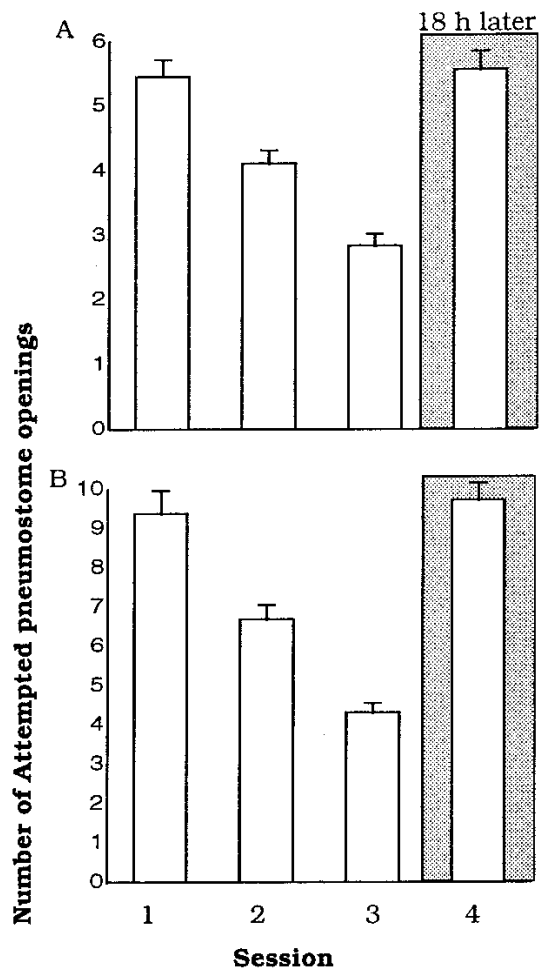

Figure 5 Access to food used as odorant does not result in an ability to retrieve memory when a different test procedure is used. (A) Snails $(n=27)$ fed carrot learn when trained with the standard hypoxic procedure but fail to show LTM when tested with the food-odorant procedure (carrot). (B) As in $A$, only the snails were trained with the food-odorant procedure and tested with the standard procedure.

$P<0.0001$; Session 3 was significantly different from Session 1: $P<0.01, n \leqslant 26$; Fig. $5 \mathrm{~A}$ ] but did not exhibit LTM. Session 4 was not significantly different from Session 1

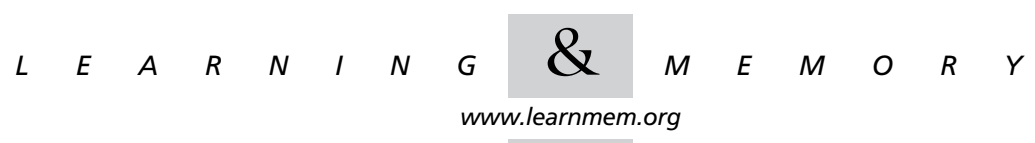


$(P>0.05)$ but was significantly different from Session 3 $(P<0.01)$.

Reversing the training and testing procedures had no effect on the outcome of LTM recall with animals fed carrot (Fig. 5B). That is, when these animals were trained with the food-odorant procedure, they exhibited learning [ANOVA, $F(2,25)=94.7567, P<0.0001$; Session 3 was significantly different from Session 1: $P<0.01$ ]. However, they did not exhibit LTM when tested with the standard hypoxic procedure (Session 4 was not significantly different from Session $1[P>0.05]$ but was significantly different from Session 3 $[P<0.01])$.

\section{Comparison of the Responsiveness of Naïve Snails}

A possible explanation of some of the differences in learning and the ability to retrieve memory between the various experimental groups of animals could have been due to differential responsiveness to hypoxia as a result of differences in the internal states of the animal. That is, it was possible for example, that food-deprived snails (presumably being hungry) might attempt to open their pneumostome significantly more often in the food-odorant procedure or vice versa. To determine if there were such differences, the data from each group of animals were compared and we determined if there were significant differences (using a two-sample t-test, independent groups with separate variances) in the number of attempted pneumostome openings in Session 1 (Fig. 6). Using the data obtained with the first group of animals (Fig. 1A) as our reference point, we found that there were no significant differences between any of the groups in their responsiveness in Session $1(P>0.05$ for each comparison). That is, each group of animals (fooddeprived vs. non-food-deprived, whether lettuce or carrot was the food source) responded (number of attempted pneumostome openings) to the different procedure (standard vs. food-odorant) similarly. Thus, any differences in the ability to learn or remember were not due to differences in the perception of the hypoxic environment as evidenced by the number of attempted pneumostome openings.

\section{Yoked Control Experiments}

We previously showed that yoked control animals do not exhibit changes in aerial respiratory behavior; however, these experiments were only performed using the standard training procedure. Thus, we performed further yoked control experiments using the food-odorant procedure on snails fed lettuce. These data, as well as data showing the yoked control data using the standard procedure, are presented in Figure 7. In these experiments, we first obtained a pretest measure of the groups' responsiveness. This was accomplished by applying a tactile stimulus to the pneumostome on each attempted pneumostome opening during a $30-\mathrm{m}$ period. We then waited $24 \mathrm{~h}$. Based on previous data

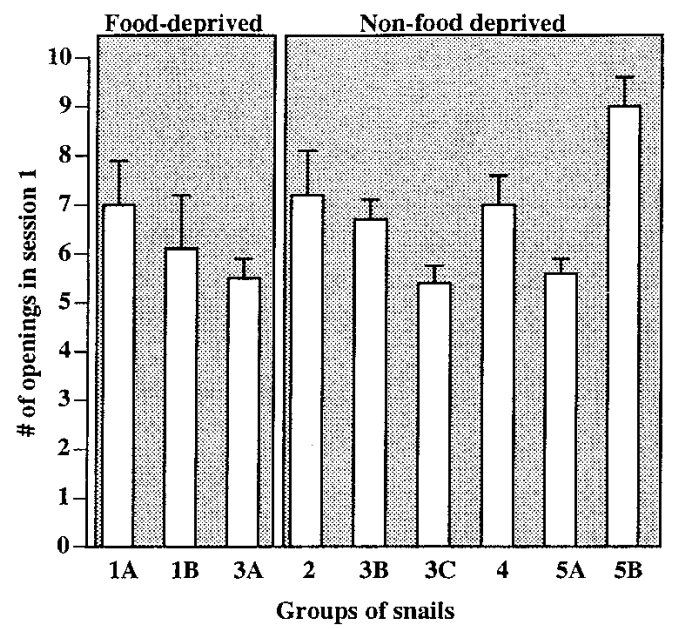

Figure 6 Comparison of the number of attempted pneumostome openings in the first training session in the nine different groups of animals used in these studies. Each group contained between 24 and 27 animals. The numbers and letters refer to the figure in which the complete data set are plotted (i.e., Sessions 1-4). An individual animal was only in one group. A comparison of the number of attempted pneumostome openings in Session 1 of each group (Group 1A was used as the reference point) revealed that there was not a significant difference in the responsiveness of any one particular group. The only group not to show learning (Group 1B: food-deprived animals trained with the food-odorant procedure) was neither the most nor the least responsive group.

(Lukowiak et al. 2000a), no learning or LTM is produced by this procedure. We then applied a poke to the pneumostome area whenever the animal yoked to the pneumostome attempted to open its. We then retested the yoked control animals $18 \mathrm{~h}$ later. As can be seen (Fig. 7), neither group of animals ( $n=12$ for each group; $A$, the standard procedure; $B$, the food-odorant procedure) showed any LTM. That is, the number of attempted openings in the pretest session was not significantly different $(A, t=0.2936, P>0.05$; B, $t=1.1022, P>0.05)$ from the number of attempted openings in the posttest period. Thus, only animals that received contingent reinforcement (the tactile stimulus to the pneumostome area as they attempted to open their pneumostome) exhibited learning or LTM.

\section{DISCUSSION}

The data obtained here allow a number of conclusions to be drawn about learning, memory formation, and memory retrieval in Lymnaea and strengthen the Lymnaea model (Benjamin et al. 2000) for the study of the neuronal mechanisms of associative learning and memory.

The first variable altered that significantly affected learning in our study was food deprivation. Food-deprived animals do not learn and thus cannot form memory and later retrieve it when trained with the food-odor procedure (Fig. 1B). Food-deprived animals do learn and remember, however, when the standard procedure is used (Fig. 1A).

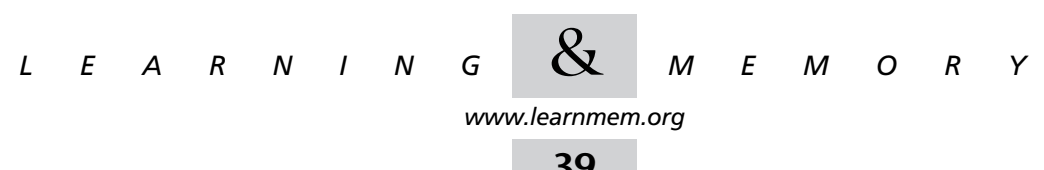




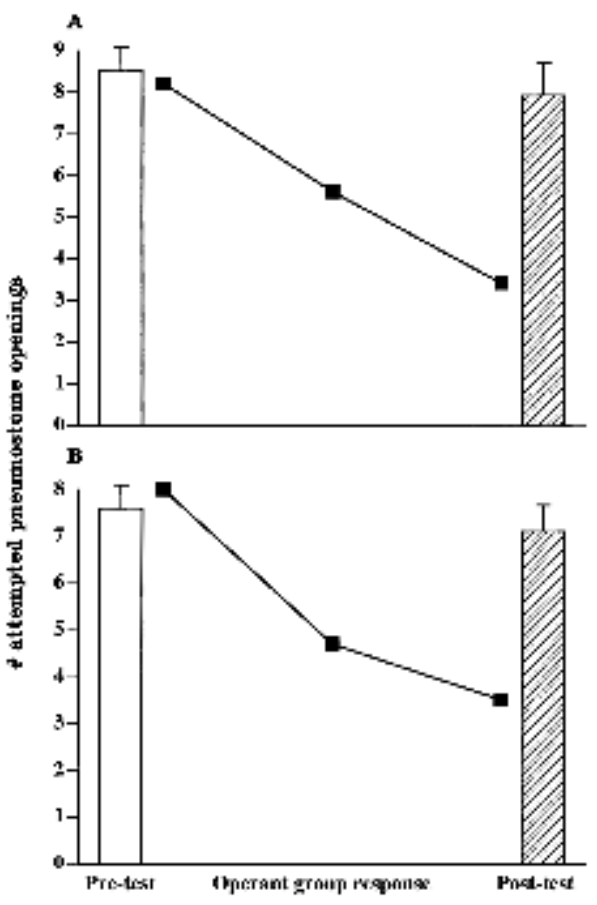

Figure 7 Yoked control animals do not exhibit learning or LTM. Two groups of animals ( $n=12$ in each group) were first given a pretest (open bar). Twenty-four hours later they received the reinforcing stimulus to their pneumostome area whenever the animal to which they were yoked to attempted to open its pneumostome. The learning curve for these operantly trained animals are plotted (filled square). Eighteen hours after the third operant training session, the yoked control animals were again tested, the posttest (shaded bar). In $A$ the standard procedure was used, while the food-odorant procedure was used in $B$.

Because statistically the same number of attempted pneumostome openings occurred in Session 1 of both groups (Fig. 6), the difference in learning ability was not due to a ceiling or basement effect brought about by the food odorant. The food odorant in the food-deprived animals interfered with the ability of the central nervous system to form an association between the activity necessary to open the pneumostome and the activity activated by the poke (the reinforcing stimulus) to the pneumostome area.

It seems obvious to even the most casual observer that a hungry animal would pay far more attention to the smell of food (e.g., Gillette et al. 2000) than to the artificial association between pneumostome openings and the poke, which is, after all, not life threatening. Not paying attention to the presentation of words in humans but to pictures instead, for example, results in an inability to learn the words (Rees et al. 1999). However, it is not clear in Lymnaea as to how this inattention translates into an inability to alter the neuronal activity of CPG neurons that are correlated with learning and memory (Spencer et al. 1999). How chemosensory input affects the activity of the respiratory CPG is also not clear. The osphradium, a sensory structure in the pneumostome area that plays a role in sensing hypoxia and activating CPG activity (Inoue et al. 1996) does not appear to play a role in appetitive learning using food odorants (Nakamura et al. 1999). Experiments now underway in our laboratory utilizing semi-intact preparations may be able to elucidate the neuronal changes brought about in CPG neurons in food-deprived animals by the food odorants that prevent learning from occurring (see below). Uncovering the mechanisms by which distracting stimuli or inattention to the stimulus prevent or impede learning and the formation of memory are of great importance in our everyday life, especially in certain clinical conditions (e.g., children exhibiting attention deficit disorder) and in education.

It was not the case that the food odorant per se prevented learning, its consolidation into LTM, and the ability to retrieve the stored memory. Fed snails learn, form LTM, and retrieve stored memory equally well with both the standard and food-odorant procedures (Figs. 2, 3A, 4). Thus although the internal state of the animal may have been altered by the lack of food, this alteration in state only had a negative impact on learning and memory when a specific training context (food odorant) was used. As in appetitive classical conditioning studies using Lymnaea (Ito et al. 1999; Staras et al. 1999), other mollusks (Susswein et al. 1986; Lechner et al. 2000) and vertebrates (Dickinson 1980) the internal state of the animal greatly influences the establishment of learning. For instance, it is much more difficult to associatively condition a well-fed animal to a neutral or repulsive stimulus than it is with a hungry animal (Dickinson 1980).

Because the food odorant, in the case of food-deprived animals, was able to interfere with the formation of learning and the establishment of LTM, we asked whether the food odorant would affect the ability to retrieve memory of an already learned behavior. Our initial hypothesis (Lukowiak et al. 1996) was that animals sensed the hypoxic environment with receptors located in the pneumostome-osphradial area (Wedemeyer and Schild 1995; Kamardin et al. 1999) and this triggered the memory (for review, see Benjamin et al. 2000). Because in both the standard and foododorant procedures, the environment is similarly hypoxic, we hypothesized that animals trained with the standard procedure would show LTM when tested with the food-odorant procedure. The data from our initial experiment testing this hypothesis (Fig. 3A) did not bear this out. Animals did not exhibit LTM. Because we employed food-deprived animals in this first series of experiments, we thought that the food odorant distracted (Rees et al. 1999) or stressed (de Quervain et al. 1998, 2000) the animals so much (they could smell the food but couldn't eat it-a stressful situation) that they could not retrieve the memory. However, as we repeated the experiments with fed animals, it became clear that this was not the case. Our data, thus, are consistent with the hypothesis that Lymnaea show context learning

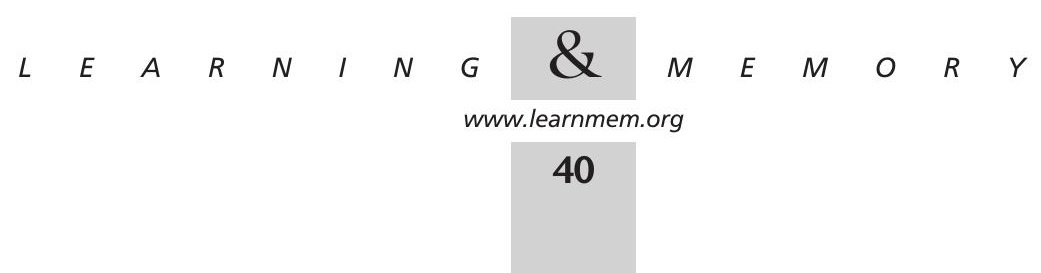


and that they do not easily generalize to another context when tested for memory. That is, the animals were unable to retrieve the memory of the learned behavior when a different context test was used.

Similar data regarding context learning and memory retrieval have now been obtained in visual learning in Drosophila, in which a switch from one monochromatic light to another blocks retrieval of the memory (Liu et al. 1999). Similarly, remembering was much better when the test situation was the same as the training situation in both $C$. elegans and Aplysia (Colwill et al. 1988; Rankin 2000). These findings of better recall when tested in the same context of the original learning are not just restricted to simpler invertebrate preparations. For example, it is easier for university students to recall a passage of prose that had been learned in the presence of an olfactory stimulus when that specific stimulus was present than when it was not (Pointer and Bond 1998). Further, students taught either in a classroom setting or a nonclassroom setting had better memory recall when the test was administered in the same setting in which learning occurred (Isarida and Isarida 1999). How this phenomena of lack of generalization occurs at the neuronal level will be the subject of future experimentation using semi-intact Lymnaea preparations in which the behavior (pneumostome activity) and neuronal activity can be directly studied simultaneously. In Drosophila and the honeybee, the mushroom bodies, in which certain forms of memory appear to be stored (DeBelle and Heisenberg 1994; Fiala et al. 1999), play a major role in allowing some context generalization to occur, as following their ablation generalization is hampered (Liu et al. 1999). Preliminary data suggest that in Lymnaea RPeD1 (one of the three CPG neurons) may play a similar role in memory storage as the mushroom bodies do in Drosophila and the honeybee (Lukowiak et al. 2000b). Thus, we expect that altering the context of the test session will alter the activity of RPeD1. Our expectation is that when tested with the trained context, activity of neuron RPeD1 (the cell that initiates respiratory activity) will be suppressed as has already been shown by Spencer et al. (1999). However, when the context is changed RPeD1 activity will rebound to normal levels of activity. The mechanisms underlying this rebound in activity will then have to be determined.

The inability to retrieve memory in our experiments with the change of context might have been due to the novelty (see Kemenes and Benjamin 1994) of the carrot odor. That is, because the animals had never experienced carrot, the odor was so new and overwhelming that it masked the memory. We, therefore, performed another set of experiments in which the snails had continuous exposure to carrot rather than lettuce as their food source (Fig. 4). Thus, carrot odor would not be a completely novel stimulus. However, exactly the same results were obtained as with animals fed lettuce (Figs. 5A,B). Changing the con- text of the test session resulted in the snails behaving as naïve animals.

As shown above, changing the context of the test session prevented the retrieval of memory. Because we tested the ability of snails to retrieve memory some $18 \mathrm{~h}$ after the last training session, we were dealing with LTM (Lukowiak et. al. 2000a). In many systems, LTM is thought to be dependent on new protein synthesis and altered gene activity (Rosenzweig et al. 1993). In the operant conditioning of aerial respiratory behavior, it was recently shown that LTM is dependent on altered gene activity and new protein synthesis (Scheibenstock and Lukowiak 2000). Thus, transcriptional blockers applied just after training prevent the formation of LTM but not intermediate-term memory (ITM). ITM, which persists for only 2-3 h in Lymnaea (Lukowiak et al. 2000a), is also dependent on new protein synthesis but not altered gene activity. Thus, using a translational blocker, Scheibenstock and Lukowiak (2000) showed that ITM could be blocked. Changes in protein synthesis that occur locally and extrasomally (Martin et al. 1997; Spencer et al. 2000) are hypothesized to underlie this form of memory. Whether a change in context will also affect the ability to retrieve ITM is now being studied using a procedure that only produces ITM (Lukowiak et al. 2000a).

These experiments and results described here extend the usefulness of operant conditioning of aerial respiration in Lymnaea as a model system in which to directly study how learning and the different forms of memory are mediated at the neuronal level. Such direct studies on the neuronal mechanisms of context learning, memory retrieval, and the effects of stress and inattention may be best initiated in our model system.

\section{MATERIALS AND METHODS}

\section{Lymnaea}

Lymnaea originally obtained from Vrije Universiteit in Amsterdam were laboratory bred in the snail facility at the University of Calgary. Snails were $25-30 \mathrm{~mm}$ in length, the same length (and thus, age) that we have used in our previous learning-and-memory experiments. The operant conditioning procedure was similar to that previously used (Lukowiak et al. 1996; Spencer et al. 1999; Lukowiak et al. 2000a; see below).

\section{Procedures for Testing Learning and Memory}

Briefly, a 1-L beaker with $500 \mathrm{~mL}$ of pond water is made hypoxic by bubbling $\mathrm{N}_{2}$ through it for $20 \mathrm{~min}$. The individually marked snails are then placed into the hypoxic water and given a 10-min acclimatization time in which they are free to perform aerial breathing. Then the snails are gently pushed under the surface and the training/testing begins. This will be referred to here as the standard procedure. The other procedure used in these studies will be referred to as the food-odorant procedure. In this procedure $\mathrm{N}_{2}$ is first bubbled through the food-odorant apparatus (see below) containing cut-up carrot before being bubbled through the training apparatus.

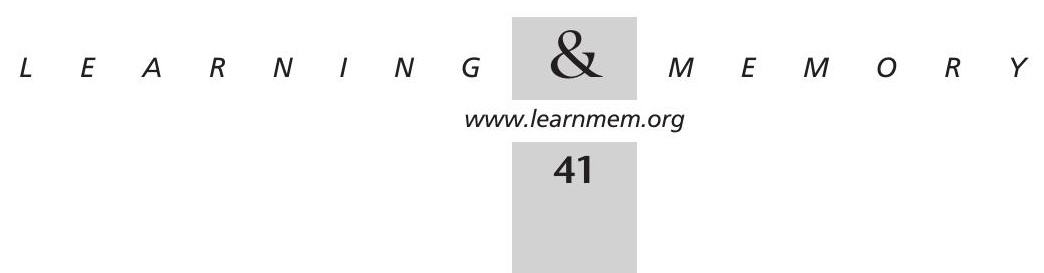


During training with either procedure, when a snail comes to the surface to breathe a tactile stimulus is applied with a sharpened wooden applicator (our digital stimulator) to the pneumostome area. This causes the animal to immediately close its pneumostome. The time of each stimulus is recorded and then tabulated. In these experiments, snails were trained three times per day (15-min training session) with a $1-\mathrm{h}$ interval between each session. This training procedure produces both ITM and LTM (Lukowiak et al. 2000a). Testing for LTM was performed $18 \mathrm{~h}$ after the last training session.

Yoked controls were performed as previously described (Lukowiak et al. 2000a) for both the standard procedure and the food-odorant procedure using snails that were not food deprived (fed lettuce) (Fig. 7). Associative learning was not seen with the yoked control procedure. Briefly, snails of the same size were randomly picked from our snail colony and assigned to one of the yoked control groups. They were then placed in the test beaker for either the standard procedure or the food-odorant procedure. The number of attempted pneumostome openings in a 30-min pretest session was then determined for each snail. Twenty-four hours later the snails were again placed in the hypoxic training beaker and a tactile stimulus applied to the pneumostome area every time the animal yoked to the pneumostome attempts to open it. There were three 30-min training sessions, each session separated by at least a 1-h rest interval. We tested the yoked control animals $18 \mathrm{~h}$ later (the posttest). In this session they received a poke to their pneumostome area whenever they attempted to open their pneumostome. We compared the number of attempted openings in the posttest with the number of attempted openings in the pretest session using a paired $t$-test comparison.

Each group of snails in all experiments, except the yoked control series shown in Figure 7 , consisted of $\sim 25$ snails. Snails were only subjected to a single series of training and testing for memory. For example, if a snail was used in the carrot-odorant procedure, it was not used for any other experiment.

\section{Food-Odorant Apparatus}

$\mathrm{N}_{2}$ is first bubbled through a 750 -mL Erlenmeyer flask filled with pond water and cut-up carrot. The flask is sealed by a rubber stopper, which has two connecting tubes (an inlet and an outlet port). The outflow is then bubbled through the training beaker. Separate systems of tubes and air-stones are used so that there is no contamination of carrot-smell associated with the apparatus used for the standard procedure. The pond water in the training beaker is made hypoxic by bubbling the food-odorant $\mathrm{N}_{2}$ through it for 20 min prior to placing the snails in it for their 10-min acclimatization period.

\section{Feeding versus Nonfeeding}

Food-deprived Lymnaea were placed into a normoxic aquarium that has never had food in it and is devoid of food for a period of $5 \mathrm{~d}$ prior to training. Non-food-deprived Lymnaea were kept in an aquarium containing a food source such as lettuce or carrot (but not both) for $5 \mathrm{~d}$ in normoxic conditions. The aquarium is supplied with food and the snails are able to eat as much as desired.

\section{Operational Definitions of Learning and Memory, and Statistics}

Learning is operationally defined as a significant effect of repeated training on the number of attempted pneumostome openings (ANOVA, $P<0.05$; followed by a post hoc Fisher's LSD protected t-test, $P<0.05$ within each separate group). Additionally, the num- ber of attempted openings in Session 3 had to be significantly less than the number of attempted openings in Session 1.

Lukowiak et. al. (2000a) defined LTM as a memory that persisted for at least $18 \mathrm{~h}$. That is, when animals were tested $18 \mathrm{~h}$ after the last training session (i.e., Session 4) the number of attempted pneumostome openings was not significantly different from the last training session (i.e., Session 3). However, both the test session (Session $4,18 \mathrm{~h}$ after the last training session) and the last training session (Session 3) had to be significantly less than the number of attempted openings in Session 1. Significant differences will be deemed when $P<0.05$.

\section{ACKNOWLEDGMENTS}

This work was supported by a grant to K.L. from MRC (Canada). We thank Drs. Q. Pittman, G. Spencer, and A. Schibenstock for discussions and comments on an earlier draft of this paper.

The publication costs of this article were defrayed in part by payment of page charges. This article must therefore be hereby marked "advertisement" in accordance with 18 USC section 1734 solely to indicate this fact.

\section{REFERENCES}

Benjamin, P., Staras, K., and Kemenes, G. 2000. A systems approach to the cellular analysis of associative learning in the pond snail Lymnaea. Learn. Mem. 7: 124-131.

Colwill, R., Absher, R., and Roberts, M. 1988. Conditional discrimination learning in Aplysia californica. J. Neurosci. 8: 4440-4444.

DeBelle, J. and Heisenberg, M. 1994. Associative odor learning in Drosophila abolished by chemical ablation of mushroom bodies. Science 263: 692-695.

de Quervain, D., Roozendaal, B., and McGaugh, J. 1998. Stress and glucocorticoids impair retrieval of long-term spatial memory. Nature 394: 787-790.

de Quervain, D., Roozendaal, B., Nitsch, R., McGaugh, J., and Hock, C. 2000. Acute cortisone administration impairs retrieval of long-term declarative memory in humans. Nature Neuroscience 3: 313-314.

Dickinson, A. 1980. Contemporary animal learning theory. Cambridge, Cambridge University Press.

Fiala, A., Muller, U., and Menzel, R. 1999. Reversible down regulation of protein kinase A during olfactory learning using antisense technique impairs long-term memory formation in the honeybee, Apis mellifera. J. Neurosci. 19: 10125-10134.

Gerber, B. and Menzel, R. 2000 Contextual modulation of memory consolidation. Learn. Mem. 7: 151-158.

Gillette, R., Huang, R.-C., Hatcher, N., and Moroz, L. 2000. Cost-benefit analysis potential in feeding behavior of a predatory snail by integration of hunger, taste, and pain. Proc. Nat. Acad. Sci. 97: 3585-3590.

Hermitte, G., Pedreira, M., Tomsic, D., and Maldonado, H. 1999. Context shift and protein synthesis inhibition disrupt long-term habituation after spaced, but not massed, training in the crab Chasmagnathus Neurobiol. Learn. Mem. 71: 34-49.

Inoue, T., Takasaki, M., Lukowiak, K., and Syed, N. 1996. Inhibition of the respiratory pattern-generating neurons by an identified whole-body withdrawal interneuron of Lymnaea stagnalis. J. Exper. Biol. 199: $1887-1898$.

Isarida, T. and Isarida, T. 1999. Effects of contextual change between class and intermission on episodic memory. Shinrigaku Kenkyu 69: 478-485.

Ito, E., Kobayashi, S., Kojima, S., Sadamoto, H., and Hatakeyama, D. 1999 Associative learning in the pond snail, Lymnaea stagnalis. Zool. Sci. 16: 711-723.

Kamardin, N., Szucs, A., and Rozsa, K. 1999. Distinct responses of osphradial neurons to chemical stimuli and neurotransmitters in Lymnaea stagnalis. Cell. Mol. Neurobiol. 19: 235-247.

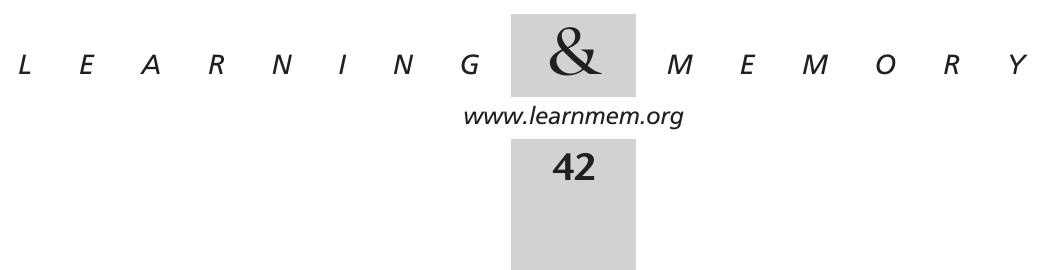


Kemenes, G. and Benjamin, P. 1994. Training in a novel environment improves the appetitive learning performance of the snail, Lymnaea stagnalis. Behav. Neural. Biol. 61: 139-149.

Lechner, H., Baxter, D., and Byrne, J. 2000. Classical conditioning in Aplysia: 1. Behavioral analysis. J. Neurosci. 20: 3369-3376.

Liu, L., Wolf, R., Ernst, R., and Heisenberg, M. 1999. Context generalization in Drosophila visual learning requires the mushroom bodies. Nature 400: 753-756.

Lukowiak, K. Ringseis, E., Spencer, G., Wildering, W. and Syed, N. 1996. Operant conditioning of aerial respiratory behavior in Lymnaea stagnalis. J. Exp. Biol. 199: 683-91.

Lukowiak, K., Cotter, R., Westly, J., Ringeis, E., Spencer, G., and Syed, N.I. 1998. Long-term memory of an operantly conditioned respiratory behavior in Lymnaea stagnalis. J. Exp. Biol. 201: 877-882.

Lukowiak, K., Adatia, N., Krygier, D., and Syed, N. 2000a. Operant conditioning in Lymnaea: Evidence for intermediate and long-term memory. Learn. Mem. 7: 140-150.

Lukowiak, K., Krygier, D., Haque, Z., Spencer, G., and Syed, N. 2000b. RPeD1 is a site for long-term memory storage of associative learning in Lymnaea. Soc. Neurosci. Abstracts (in press).

Mackintosh, N.J. 1974. The Psychology of Animal Learning. Academic Press, London.

Martin, K., Casadio, A., Zhu, H., Yaping, E., Rose, J., Chen, M., Bailey, C., and Kandel, E. 1997. Synapse-specific long-term facilitation of Aplysia sensory to motor synapses: A function for local protein synthesis in memory storage. Cell 91: 927-938.

Murphy, J., Pagno, M., Nachmani, J., Sperling, P., Kane, S., and Kleinman, R. 1998. The relationship of school breakfast to psychosocial and academic functioning: Cross-sectional and longitudinal observations in an inner-city school sample. Arch. Pediatr. Adolesc. Med. 152: 899-907.

Nakamura, H., Kojima, S., Kobayashi, S., Ito, I., Fujito, Y., Suzuki, H., and Ito, E. 1999. Physiological characterization of lip and tentacle nerves in Lymnaea stagnalis. Neurosci. Res. 33: 291-298.

Pointer, S.C. and Bond, N.W. 1998. Context-dependent memory: Colour versus odor. Chem. Senses 23: 359-362.

Powell, C., Walker, S., Chang, S., and Grantham-McGregor, S. 1998.
Nutrition and education: A randomized trial of the effects of breakfast in rural primary school children. Am. J. Clin. Nutr. 68: 873-879.

Rankin, C. 2000. Context conditioning in habituation in the nematode Caenorhabditis elegans. Behav. Neurosci. 114: 496-505.

Rees, G., Russell, C., Frith, C., and Driver, J. 1999. Inattentional blindness versus inattentional amnesia for fixated but ignored words. Science 286: 2504-2507.

Rosenzweig, M., Bennett, E., Colombo, P., Lee, D., and Serrano, P. 1993. Short-term, Intermediate term, and long term memories. Behav. Brain Res. 57: 193-198.

Sahley, C., Martin, K., and Gelperin, A. 1990. Analysis of associative learning in the terrestrial mollusc Limax maximus. II. Appetitive learning. J. Comp. Physiol. 167: 339-345.

Scheibenstock, A. and Lukowiak, K. 2000. The effects of protein synthesis blockers on intermediate and long-term memory of associative memory in Lymnaea. (in press)

Spencer, G., Syed, N., and Lukowiak, K. 1999. Neural changes after operant conditioning of the aerial respiratory behavior in Lymnaea stagnalis. J. Neurosci. 19: 1836-1843.

Spencer, G., Syed, N., van Kesteren, E., Lukowiak, K., Geraerts,W.P.M., and van Minnen, J. 2000. Synthesis and functional integration of a neurotransmitter receptor in isolated invertebrate axons. J. Neurobiol. 44: 72-81.

Staras, K., Kemenes, G., and Benjamin, P. 1999. Cellular traces of behavioral classical conditioning can be recorded at several specific sites in a simple nervous system. J. Neurosci. 19: 347-357.

Susswein, A., Schwarz, M., and Feldman, E. 1986. Learned changes of feeding behavior in Aplysia in response to edible and non-edible foods. J. Neurosci. 6: 1513-1527.

Syed, N., Bulloch, A., and Lukowiak, K. 1990. In vitro reconstruction of the respiratory central pattern generator of the mollusk Lymnaea. Science 250: 282-285.

Wedemeyer, H. and Schild, D. 1995. Chemosensitivity of the osphradium of the pond snail Lymnaea stagnalis. J. Exp. Biol. 198: 1743-1754.

Received June 19, 2000; accepted in revised form October 16, 2000. 


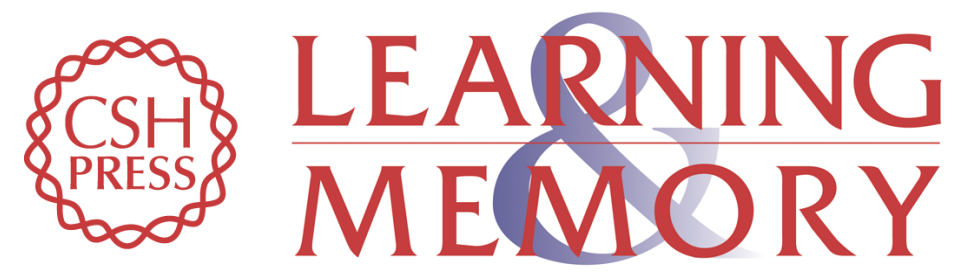

\section{Context Learning and the Effect of Context on Memory Retrieval in Lymnaea}

James Haney and Ken Lukowiak

Learn. Mem. 2001, 8:

Access the most recent version at doi:10.1101//m.34701

References This article cites 34 articles, 18 of which can be accessed free at:

http://learnmem.cshlp.org/content/8/1/35.full.html\#ref-list-1

License

Email Alerting Receive free email alerts when new articles cite this article - sign up in the box at the Service top right corner of the article or click here. 